\title{
PENYULUHAN PEMBERIAN BABY MASSAGE DALAM MENINGKATKAN KUALITAS TIDUR BAYI USIA 11 - 25 BULAN DI POSYANDU HARAPAN BUNDA
}

\author{
${ }^{1)}$ Eka Widya Ningrum, ${ }^{2)}$ Arif Pristianto \\ ${ }^{1,2)}$ Program Studi Profesi Fisioterapi, Fakultas Ilmu Kesehatan, Universitas Muhammadiyah Surakarta \\ ${ }^{1,2)}$ Jl. Ahmad Yani, Pabelan, Kartasura, Surakarta, Jawa Tengah - Indonesia \\ Email : ekabagaskara04@gmail.com,arif.pristianto@ums.ac.id
}

\begin{abstract}
ABSTRAK
Kebutuhan yang sangat penting saat masa bayi yakni tidur, karena proses pertumbuhan dan perkembangan dapat dicapai dengan maksimal dengan kualitas tidur yang baik. Pemberian baby massage digunakan sebagai salah satu metode dalam memperbaiki kualitas tidur bayi. Teknik baby massage adalah memberikan sentuhan lembut pada kulit bayi agar menstimulus sirkulasi darah dan meningkatkan pasokan oksigen yang lebih banyak ke otak sehingga mempercepat sistem sirkulasi dan pernapasan yang baik. Rasa rileks dan nyaman akibat sentuhan massage mampu meningkatkan kualitas tidur bayi, meningkatkan imunitas atau kekebalan tubuh serta meningkatkan berat badan bayi. Tujuan penelitian ini untuk mengetahui manfaat baby massage dalam meningkatkan kualitas tidur bayi usia 11 - 25 bulan. Metode kegiatan penyuluhan dengan memberikan edukasi di posyandu harapan bunda dan melakukan kunjungan ke rumah para ibu untuk pemberian baby massage serta membagikan kuisioner. Hasil kegiatan penyuluhan ini didapatkan tingkat pengetahuan pengetahuan para ibu tentang peran fisioterapi dan manfaat baby massage dalam kategori kurang dengan persentase 59\% serta kualitas tidur pada balita rata - rata dalam kategori baik dengan persentase 73\%. Simpulan dari kegiatan penyuluhan ini bahwa pemberian baby massage dapat meningkatkan kualitas tidur bayi usia 11 - 25 bulan.
\end{abstract}

Kata Kunci: baby massage, tidur, kualitas tidur

\begin{abstract}
A very important need during infancy is sleep, because the process of growth and development can be achieved with maximum quality sleep. Baby massage is used as one of the methods in improving the quality of baby's sleep. The baby massage technique is to give a gentle touch to the baby's skin to stimulate blood circulation and increase the supply of more oxygen to the brain so as to speed up the good circulatory and respiratory systems. A sense of relaxation and comfort due to massage touch can improve the quality of the baby's sleep, increase immunity or immunity and increase the baby's weight. The purpose of this study is to find out the benefits of baby massage in improving the quality of sleep of babies aged 11 - 25 months. Method of counseling activities by providing education at the mother's hope posyandu and making visits to the mothers' homes for the provision of baby massage and sharing questionnaires. The results of this extension activity obtained the level of knowledge of mothers about the role of physiotherapy and the benefits of baby massage in the category of less with a percentage of $59 \%$ and the quality of sleep in toddlers averaged in the good category with a percentage of $73 \%$. Concluded from this extension activity that giving baby massage can improve the quality of sleep of babies aged 11 - 25 months.
\end{abstract}

Keyword: baby massage, sleep, sleep quality

\section{PENDAHULUAN}

Pertumbuhan dan perkembangan pada masa bayi sangat penting untuk diperhatikan. Beberapa faktor yang dapat mempengaruhi tumbuh kembang bayi yakni istirahat dan tidur. Aspek kualitas tidur perlu diperhatikan, bukan hanya aspek kuantitas saja. Dampak sensorik dan motorik pada masa pertumbuhan dan perkembangan bayi yakni pertambahan berat dan tinggi badan, struktur gigi dan tulang, kemampuan mengangkat kepala dan tengkurap, duduk, tertawa serta menoleh jika di panggil ataupun mendengar sumber suara. Bayi beradaptasi dengan lingkungan nya yakni dengan tidur. Namun permasalahan yang sering terjadi pada malam hari bayi sulit sekali untuk tidur, hal ini dapat memicu adanya gangguan perilaku, tumbuh kembang serta gangguan otak [1]. 
Tidur sebagai salah satu rangsangan untuk pertumbuhan otak. Tubuh anak saat tidur mampu memproduksi hormon pertumbuhan sekitar 75\%. Hormon ini berperan dalam merangsang pertumbuhan jaringan dan tulang, memperbaiki metabolisme tubuh serta otak. Fungsi hormon pertumbuhan juga membantu proses perbaikan semua sel yang ada dalam tubuh. Proses perbaikan sel ini akan berlangsung lebih cepat saat bayi tertidur daripada saat terbangun [2].

Di Indonesia permasalahan tidur pada bayi cukup besar, yakni sekitar $44,2 \%$ bayi mengalami gangguan tidur seperti sering terbangun di malam hari. Studi terdahulu melakukan penelitian dengan jumlah responden 285 bayi dan diperoleh data 51,3\% bayi mengalami gangguan tidur, $42 \%$ bayi dengan tidur malamnya kurang dari 9 jam, dan pada malam hari bayi terbangun lebih dari 3 kali dengan lama bangun lebih dari satu jam [3]. Berdasarkan studi pendahuluan pada tanggal 14 November 2020 di Posyandu Harapan Bunda Desa Dabuk Rejo dengan membagikan kuisioner kepada 22 ibu bayi, 5 ibu bayi menjawab kualitas tidur bayi dalam kategori baik, 14 bayi dalam kategori cukup, dan 3 bayi dalam kategori kurang.

Waktu tidur bagi perkembangan bayi sangat penting untuk diperhatikan, maka kualitas tidur bayi harus terpenuhi dengan baik agar tidak berpengaruh buruk terhadap pertumbuhan dan perkembangannya. Kualitas tidur yang buruk akan mengakibatkan gangguan keseimbangan fisiologi dan psikologi. Adapun beberapa dampak fisiologi tersebut yakni rasa lelah, penurunan aktivitas sehari-hari, koordinasi neuromuskular yang buruk, daya tahan tubuh menurun dan proses penyembuhan melambat. Sedangkan dampak psikologinya yakni cemas, emosi yang labil, tidak konsentrasi, kemampuan kognitif melemah [1].

Adapun cara terapi non farmakologis agar mengoptimalkan kualitas tidur bayi yakni dengan pemberian baby massage. Sentuhan dari pijatan lembut akan mengendurkan otot-otot pada bayi sehingga memberikan efek rasa tenang dan tidurnya menjadi lebih nyenyak. Jika tidur nya lebih lelap maka pada saat terbangun daya konsentrasi nya akan lebih penuh [4].

Pemberian baby massage agar menstimulus kekebalan tubuh pada bayi dengan pemberian pijatan lembut sekitar 15 menit agar bayi merasa lebih nyaman, terlelap tidurnya, perkembangan dan pertumbuhannya semakin optimal [5]. Pijatan lembut pada bayi juga mempengaruhi sistem saraf dari tepi hingga ke pusat. Tekanan pada reseptor saraf di kulit akan menyebabkan pelebaran vena, arteri dan kepiler sehingga akan menghambat penyempitan, melemaskan ketegangan otot, melambatkan detak jantung dan meningkatkan gerakan usus di saluran pencernaan [6].

Fisioterapi berperan dalam segala aspek kehidupan masyarakat lainnya, tidak hanya pada subyek sehat maupun subyek sakit saja. Penulis tertarik tentang pengaruh pemberian baby massage dalam meningkatkan kualitas tidur balita di Posyandu Harapan Bunda. Rumusan Masalah yang akan diteliti adalah : "Adakah manfaat pemberian baby massage terhadap peningkatan kualitas tidur pada bayi”. Tujuan penyuluhan ini adalah pemberian edukasi kepada para ibu bayi tentang pentingnya baby massage pada bayi dan untuk mengetahui efek pemberian baby massage pada bayi usia 11 - 25 bulan.

Sasaran objek kegiatan ini adalah para ibu yang memiliki balita dan mengikuti posyandu Harapan Bunda di Blok I Desa Dabuk Rejo. Berdasarkan buku registrasi posyandu terdapat 22 balita. Para ibu yang memiliki balita dan mengikuti posyandu merupakan warga yang tinggal di Blok I dan Blok J Desa Dabuk Rejo dengan rentang usia balita dari 11 - 24 bulan. 
Kegiatan posyandu dilaksanakan setiap bulan pada tanggal 14, pada pukul 08.30 WIB selesai.

Sasaran objek penyuluhan ini yaitu para ibu yang memiliki balita dan mengikuti posyandu Harapan Bunda di Blok I Desa Dabuk Rejo. Berdasarkan buku registrasi posyandu terdapat 22 balita. Para ibu yang memiliki balita dan mengikuti posyandu merupakan warga yang tinggal di Blok I dan Blok J Desa Dabuk Rejo dengan rentang usia balita dari 11 - 24 bulan. Kegiatan posyandu dilaksanakan setiap bulan pada tanggal 14, pada pukul 08.30 WIB - selesai.

Setelah berbincang dengan kepala kader posyandu, penulis mendapatkan informasi mengenai permasalahan yang ada di posyandu, sebagai berikut :

1. Posyandu ini kurang efektif dikarenakan sedikitnya kader posyandu, fasilitas yang kurang memadai seperti tidak ada alat pengukur panjang bayi, timbangan digital, dan alat pengukur lingkar kepala, kemudian kegiatan yang monoton dengan waktu yang singkat.

2. Dikarenakan kondisi ibu adalah wanita karir atau sedang ada kesibukan lain sedangkan pelaksanaan posyandu di hari kerja otomatis banyak para ibu yang tidak hadir dalam posyandu untuk memantau kesehatan anaknya.

3. Terdapatnya empat tenaga kesehatan yang buka praktik di lingkungan Desa Dabuk Rejo membuat para ibu lebih memilih pergi ke tenaga kesehatan walaupun harus membayar karena malas untuk mengantri terlalu lama.

4. Kurangnya pengetahuan para ibu tentang tumbuh kembang dan manfaat massage khususnya dalam segi fisioterapi, karena sedikitnya tenaga kesehatan atau mahasiswa yang melakukan penyuluhan tentang kesehatan di daerah penulis.

\section{METODE PELAKSANAAN}

Dalam rangka mencapai tujuan yang telah diuraikan di atas, maka pelaksanaan kegiatan penyuluhan kepada masyarakat ini dilakukan dengan metode deskriptif yaitu memberikan penjelasan manfaat baby massage menggunakan media leaflet yang di desain oleh penulis serta mengenalkan peran fisioterapi kepada para ibu. Terdapat dua metode yang di terapkan dalam program ini, yaitu metode presentasi dan mengunjungi atau visit ke rumah para ibu. Adapun kerangka kerja kegiatan sebagai berikut,

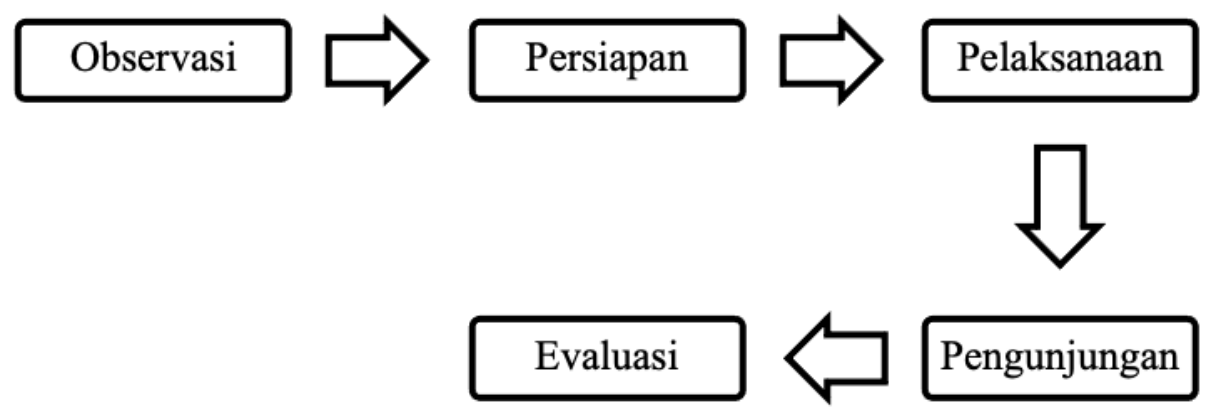

Gambar 1. Kerangka Kerja Kegiatan Penyuluhan

\section{HASIL}


Hasil penyuluhan disajikan dalam beberapa bagian yakni data umum dan khusus. Data umum berisi umur, jenis kelamin, status kesehatan. Data khusus menyajikan kualitas tidur balita usia 11 - 25 bulan sebelum dilakukan massage dan setelah diberikan massage, serta tingkat pengetahuan para ibu mengenai fungsi dan peran fisioterapi.

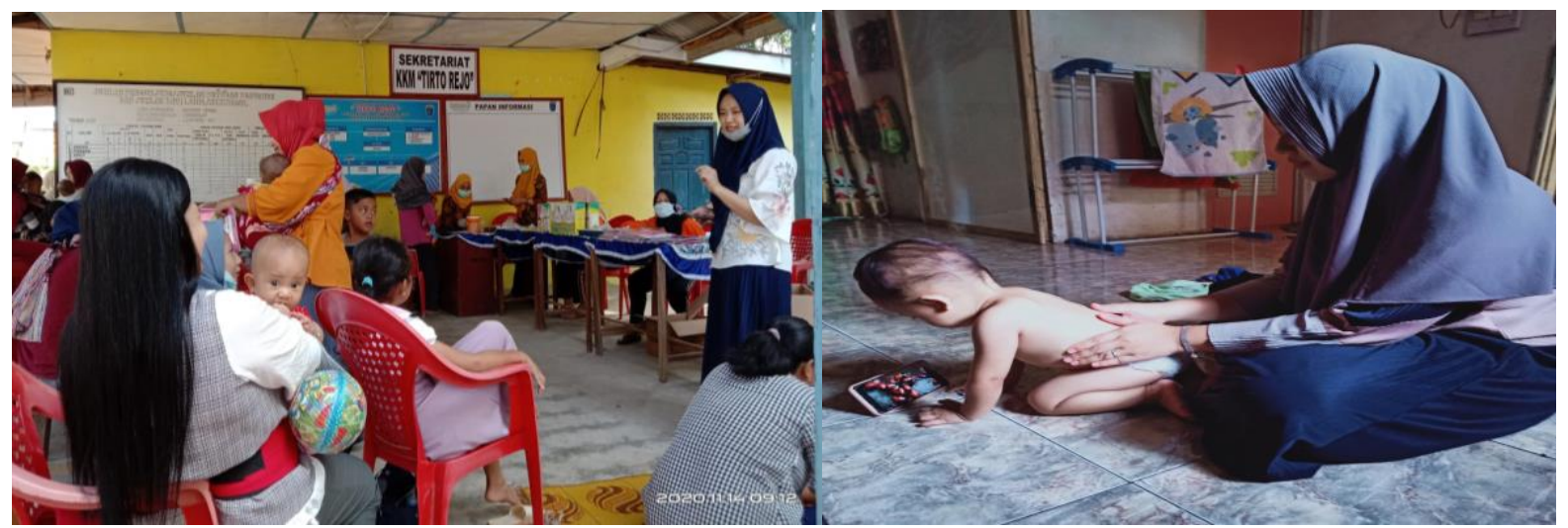

Gambar 2. Pelaksanaan Kegiatan Penyuluhan

Penyuluhan ini dilaksanakan pada 14 November 2020, jam 08.30 WIB dengan tujuan untuk meningkatkan peran serta Fakultas Ilmu Kesehatan, khususnya Progam Studi Profesi Fisioterapi Universitas Muhammadiyah Surakarta dalam memberikan pengetahuan dan informasi kepada orangtua khususnya para ibu, tentang teknik dan manfaat pemberian massage terhadap peningkatan kualitas tidur pada bayi usia 11 - 25 bulan serta peran fisioterapi dalam masyarakat. Prosedur yang dilakukan dalam kegiatan penyuluhan ini yakni dengan membagikan leaflet dan kuisioner di tanggal 14 November 2020, kemudian pada tanggal 15 - 25 November melakukan kunjungan atau visit ke rumah orangtua untuk pemberian baby massage dan membagikan kuisioner.
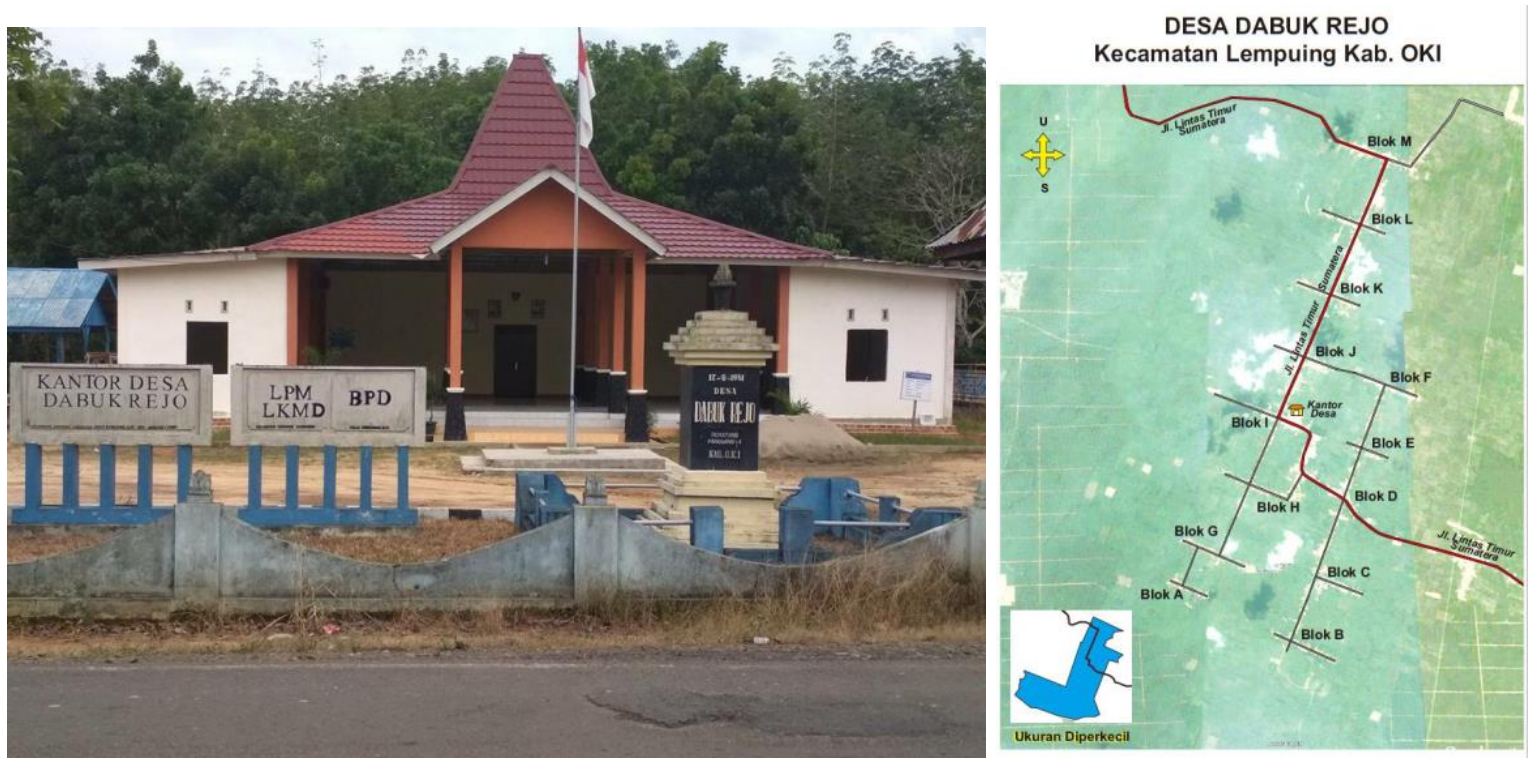

Gambar 3. Lokasi Kegiatan

Lokasi kegiatan penyuluhan yakni di Balai Desa Dabuk Rejo tepatnya di Jln. Lintas Timur Blok I Desa Dabuk Rejo, Kecamatan Lempuing Kab. Ogan Komering Ilir, Palembang- 
Sumatera Selatan. Penulis memanfaatkan kegiatan posyandu balita yang diadakan setiap bulan di Desa Dabuk Rejo untuk memberikan penyuluhan tentang manfaat baby massage dan peran fisioterapi dalam masyarakat.

1. Data Umum

Tabel 2. Karakteristik responden berdasarkan usia

\begin{tabular}{cccc}
\hline No & Umur & Frekuensi & Persentase (\%) \\
\hline 1 & $11-13$ bulan & 4 & $18 \%$ \\
2 & $14-16$ bulan & 7 & $32 \%$ \\
3 & $17-19$ bulan & 7 & $32 \%$ \\
4 & $20-22$ bulan & 3 & $13 \%$ \\
5 & $23-25$ bulan & 1 & $5 \%$ \\
\multicolumn{2}{l}{ Total } & 22 & $100 \%$ \\
\hline
\end{tabular}

Tabel 3. Karakteristik responden berdasarkan jenis kelamin

\begin{tabular}{cccc}
\hline No & Jenis Kelamin & Frekuensi & Persentase (\%) \\
\hline 1 & Laki - laki & 11 & $50 \%$ \\
2 & Perempuan & 11 & $50 \%$ \\
& Total & 22 & $100 \%$ \\
\hline
\end{tabular}

Tabel 4. Karakteristik responden berdasarkan status kesehatan

\begin{tabular}{cccc}
\hline No & Status Kesehatan & Frekuensi & Persentase (\%) \\
\hline 1 & Sehat & 22 & $100 \%$ \\
2 & Sakit & 0 & $0 \%$ \\
& Total & 22 & $100 \%$ \\
\hline
\end{tabular}

2. Data Khusus

Tabel 5. Kualitas tidur balita sebelum dilakukan baby massage

\begin{tabular}{cccc}
\hline No & Pre Test & Frekuensi & Presentase (\%) \\
\hline 1 & Baik & 5 & $23 \%$ \\
2 & Cukup & 14 & $64 \%$ \\
3 & Kurang & 3 & $13 \%$ \\
& Total & 22 & $100 \%$ \\
\hline
\end{tabular}

Tabel 6. Kualitas tidur balita setelah dilakukan baby massage

\begin{tabular}{cccc}
\hline No & Post Test & Frekuensi & Presentase (\%) \\
\hline 1 & Baik & 16 & $73 \%$ \\
2 & Cukup & 6 & $27 \%$ \\
3 & Kurang & 0 & $0 \%$ \\
& Total & 22 & $100 \%$ \\
\hline
\end{tabular}

Tabel. 7. Pengetahuan para ibu tentang peran fisioterapi dan manfaat baby massage 


\begin{tabular}{cccc}
\hline No & Tingkat pengetahuan & Frekuensi & Presentase (\%) \\
\hline 1 & Baik & 4 & $18 \%$ \\
2 & Cukup & 5 & $23 \%$ \\
3 & Kurang & 13 & $59 \%$ \\
& Total & 22 & $100 \%$ \\
\hline
\end{tabular}

\section{KESIMPULAN}

Penulis merumuskan simpulan dari hasil kegiatan penyuluhan di posyandu Harapan Bunda sebagai berikut :

1. Hasil data responden atau para ibu menunjukkan bahwa rata - rata tingkat pengetahuan tentang peran fisioterapi dan manfaat massage dalam kategori "Kurang" yakni sebanyak 59\% karena minim nya lulusan fisioterapi di daerah penulis dan para ibu mempercayakan pemberian massage pada tukang pijat bayi atau dukun beranak yang mereka rasakan dampak pemberiaan pijat tersebut.

2. Hasil data pre test responden menunjukkan bahwa rata-rata kualitas tidur pada balita dalam kategori "Cukup" sebanyak 64\% dan setelah dilakukan post test rata-rata tingkat kualitas tidur balita dalam kategori "Baik" sebanyak 73\%, maka dalam kegiatan penyuluhan ini didapatkan kesimpulan adanya pengaruh pemberian baby massage dalam meningkatkan kualitas tidur bayi usia 11- 25 bulan di Posyandu Harapan Bunda.

\section{DAFTAR PUSTAKA}

[1] Muawwanah, Siti; Zaimsyah, Futhri Rifa; Samosir, Nova Relida;. (2019). Efek Pemberian Massage Bayi Dapat Meningkatkan Kualitas Tidur Bayi Normal Usia 0 - 6 Bulan Di Posyandu Permata Hati. Jurnal Pengabdian Masyarakat Multidisiplin, 125 131.

[2] Irianti, Berliana; Karlinah, Nelly;. (2021). Efektivitas Pijat Terhadap Kualitas Tidur Bayi (0-1 Tahun) Di PMB Hasna Dewi Tahun 2020. Ensiklopedia Of Journal, 1-6.

[3] Natalita C; Sekartini R; Poesponegoro H;. (2011). Skala gangguan tidur untuk anak (sdsc) sebagai instrumen skrining gangguan tidur pada anak sekolah lanjutan tingkat pertama. Sari Pediatri, 365-372.

[4] Roesli, U. 2013. Pedoman Pijat Bayi Edisi Revisi. Jakarta : Trubus Agriwidya

[5] Riksani, R. 2012. Cara Mudah dan Aman Pijat Bayi. Jakarta : Niaga Swadaya

[6] Field, T;. (2017). Newborn Massage Therapy. International Journal of Pediatrics and Neonatal Health, 54-64. 